University of Louisville

ThinkIR: The University of Louisville's Institutional Repository

Electronic Theses and Dissertations

$5-1912$

\title{
An abbreviated scheme for the detection of acid radicals.
}

Mary Pressley Smith

University of Louisville

Follow this and additional works at: https://ir.library.louisville.edu/etd

\section{Recommended Citation}

Smith, Mary Pressley, "An abbreviated scheme for the detection of acid radicals." (1912). Electronic Theses and Dissertations. Paper 1357.

https://doi.org/10.18297/etd/1357

This Master's Thesis is brought to you for free and open access by ThinkIR: The University of Louisville's Institutional Repository. It has been accepted for inclusion in Electronic Theses and Dissertations by an authorized administrator of ThinkIR: The University of Louisville's Institutional Repository. This title appears here courtesy of the author, who has retained all other copyrights. For more information, please contact thinkir@louisville.edu. 


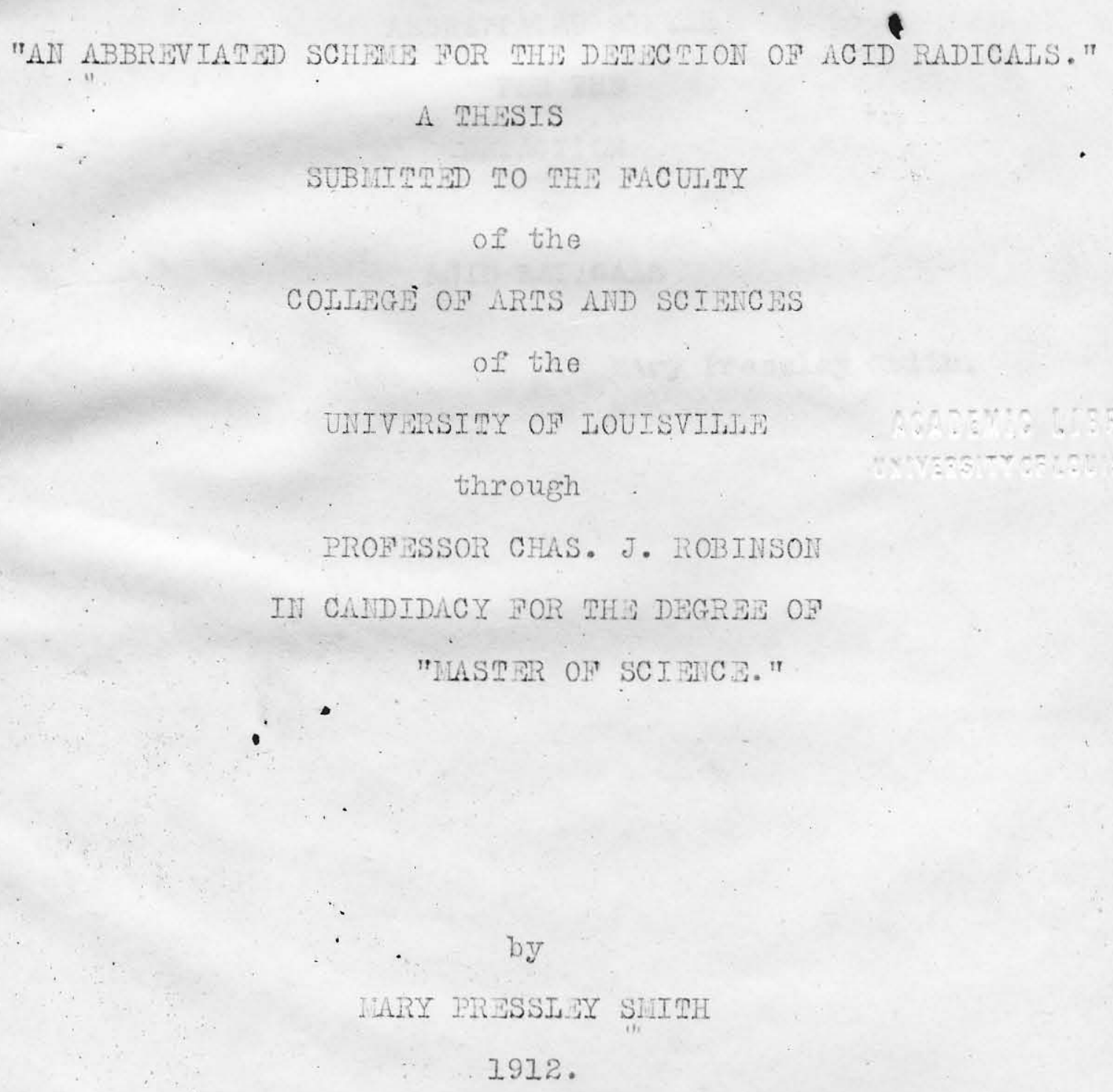


AN

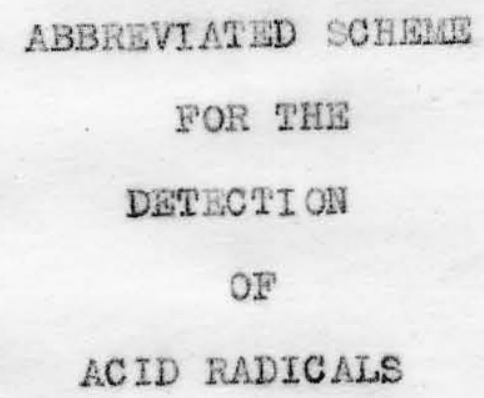

Mary Pressloy Snith. 
In studying qualitative chemistry, two things impress you. The one being, the systonatic, inclusive and generally accepted tables for the detectionand identification of the several metals; the other, the lack of any agreement as to the mothod of the identificationbf acid radicals. The metal analysis tables are so well arranged and so true that oven the inexperiended person finds little or no difficulty in working with them. But with the acid radieals, it is an entirely different proposition. There Is no generally accepted grouping of the radicals into divisions, some text books giving as many as seven divisions and some none at all. The tests given are, in some instances, not at all satisfactory. And we find dissatisfaction anong pupils in regard to their acid radical work. .

Now the detection of the non metalle portion of a compound is just as essential to the identification of a substance as that of the netalle. With this Idea in view I have been working on the following table complled by Dr. Robinsonfor use in the medical and academie laboratories of the University of Louisvillo.

ANALYTICAL TABLE V. Tests for Acid Radicals.

If the original solutioneontains metals other that the alkalies, add to about $500 \mathrm{c.c}$. of $1 \mathrm{t}$ enough $\mathrm{Na}_{2} \mathrm{CO}_{3}$ to make strongly alkaline, bo11 10 to 15 minutes, renewing water lost by ovaporation and filter. Use this prepared solution for the acid analysis, except for the earbonate test, and when especially directed to use the orlginal solution.

Perform the tests in the order indicated.

$\neq$ means take fresh portion of the prepared solution. 1. To portion of unacidified original solution, add Bacl2. If no precipitste forms, proced ab once to 11. If prec. occurs, or if original solution contalns acid, work through $A, B, C$, D. If solution is acid, omit $A$.

$A \neq$ To portion of prepared solution add HCl (to slight $\phi \neq \phi \phi \phi \phi$ acid- 
ity). Efforvescenco indicates (unless $\mathrm{Na}_{2} \mathrm{CO}_{3}$ was addedabove):

1. $=\boldsymbol{C}_{3}$. Passing gas into lime water gives precipitation.

- Gas has no effect on $\mathrm{KnTO}_{4}$.

Precipitate of sulphur indicates:

2. $=\mathrm{S}_{3} \mathrm{O}_{3}$. Heated gives $\mathrm{SO}_{8}$. $\mathrm{KMnO}_{4}$ when added decolorized.

3. $=5 \mathrm{x}$

4. $=\$+$ oxidizing agent

See II E I.

$\mathrm{B}$ Filter clear and add $\mathrm{BaCl}$. White pree. indicates

1. $\mathrm{SSO}_{4}$.

c. Filter olear, boll to remove $\mathrm{CO}_{3}$ add $\mathrm{CqCl}_{3}$ and $1-2$ grams of sodium acetate. Prec. Indicates:

1. $=\mathrm{C}_{2} \mathrm{O}_{4}$. Filter, wash, treat prec. with dilute $\mathrm{H}_{2} \mathrm{SO}_{4}$,

warm and add $\mathrm{KunO}_{4}$. Decolorized.

2. $=\mathrm{Cr}_{3} \mathrm{O}_{\mathrm{r}}$ if yellow. Filter, wash, dissiolve in $\mathrm{HCl}$ and add $\mathrm{H}_{2} \mathrm{O}_{2}$. Transiont blue color.

3. $=\mathrm{SIO}_{3}$. Metaphosphate bead (microsomic selt) gives "skeleton". D. Filter clear, make alkaline with $\mathrm{Ba}(\mathrm{OH})_{2}$ (use litmus).

Proc. Indicates:

1. $\mathrm{EPO}_{4}$. $\neq$ Acldify with $\mathrm{HNO}_{3}$. Ammonium molybdate and heat gives yellow pree.

2. $\equiv \mathrm{AsO}_{4} \cdot \neq$ same as $\equiv \mathrm{PO}_{4} \cdot \neq$ Add cone. $\mathrm{HCl}$ and $\mathrm{H}_{2} \mathrm{~S}$. Yellow pree. $\mathrm{AS}_{2} \mathrm{~S}_{5}$.

3. $=\mathrm{SO}_{3} \cdot \neq \mathrm{H}_{2} \mathrm{SO}_{4}$ and heat gives $\mathrm{SO}_{2}$. $\mathrm{KnnO}_{4}$ decolorized.

4. $\mathrm{BBO}_{3}$ or $\mathrm{B}_{4} \mathrm{O}_{7} \neq$ Solid material or solution evaporated. to very small volume eives with conc. $\mathrm{H}_{8} \mathrm{SO}_{4}$ and alcohol, a green flame when ignited.

5. $=\mathrm{C}_{4} \mathrm{H}_{4} \mathrm{O}_{6}$. Dissolved prec. In $\mathrm{HNO}_{3}$, add $\mathrm{AgNO}_{3} ; \mathrm{NaOH}$ un- 
t1l nalkaline: $\mathrm{NH}_{4} \mathrm{OH}$ unt1l prec. dissolves and boll. Silver mirror.

E. S11ver pree. dark, or darkens when heated, indicates:

1. $=\mathrm{S}$. $\neq \mathrm{H}_{8} \mathrm{SO}_{4}$ and heat gives $\mathrm{H}_{2} \mathrm{~S}$. Lead acetate paper blackened

by vapors.

2. $=\mathrm{S}_{3} \mathrm{O}_{3} \cdot \neq \mathrm{H}_{2} \mathrm{SO}_{4}$ and heat gives prec. of $\mathrm{S}$ and $\mathrm{SO}_{2}$. $\mathrm{KMnO}_{4}$

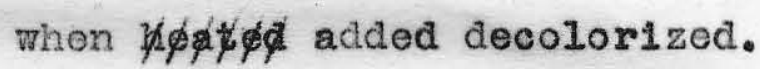

F. f gives marked color with HCL and FeCl $\mathbf{l}_{3}$

3. -SCN. Blood red solution with $\mathrm{FeCl}_{3}$ and ECl.

2. $\equiv \mathrm{Fe}(\mathrm{CN})_{6}$ Dark blue pree. With $\mathrm{FeCl}_{3}$ and HCl.

3. $\mathrm{Fe}(\mathrm{CN})_{6} \cdot \mathrm{DIrty}$ brown. prec. $\mathrm{HCI}$ and $\mathrm{FeSO}_{4}$ deep blue precipitate.

4. -I. Brown with HCI and $\mathrm{FeCl}_{3}$. Chloroform added and shaken assumes violet color. $\neq$ Silver pree. Yellow.

G. F Neutral solution with $\mathrm{FeCl}_{3}$ alone. Brown color Indicates

1. $-\mathrm{C}_{2} \mathrm{H}_{3} \mathrm{O}_{2}$ - Brownish-red solution. Pree when boiled. SeeIII $4:$

2. $-\mathrm{NO}_{3}$. Reddish brown. Pree. on shaking, hastened by heat. SeeIII 2.

H. $\neq$ With $\mathrm{NaOH}, \mathrm{FOSO}_{4}, \mathrm{FeCl}_{3}$ and $\mathrm{HCl}$, blue pree. indieatos

1. $-\mathrm{N}$. ( Not applicable in presence of $\mathrm{F} 2$ and 3 ).

I. F gives $c i$ with acids and heat (starch-iodide paper in vapors

turns blue) indicates:

1. C10. F Acidifled, bleaches indigo solution.

K. F Chlorine water and chloroform added to slightly acidified solution; color in latter indicates:

1. -Br intes chloroform brown color.

2. + I * violet color. Carefully add excess

of chlorine water until violet disappears. $\left(\mathrm{ICl}_{3}\right)$.

If brown remains, both $-B \mathrm{r}$ and $-\mathrm{I}$ are present. 
L. If all previous tests in section II are negative, the silver prec. must be $\mathrm{AgCl}$, indicating $\mathrm{Cl}$. Pree. readily soluble in $\mathrm{NH}_{4} \mathrm{OH}$. If other acid radicals of theis section are present, mix a portion of dry substance (or residue left by evaporation of solution) with powdered $\mathrm{K}_{2} \mathrm{Cr}_{2} \mathrm{O}_{7}$ in dry test-tube, add $5 \mathrm{cc}$. cone. $\mathrm{H}_{2} \mathrm{SO}_{4}$ and warm. Pour brown funes into water, shake and add $\mathrm{H}_{2} \mathrm{O}_{2}$. Blue color indicates $\alpha$ Cl. ( Dangerous if chlorates are present. Apply test III 3 to detect chlorates).

III. Ac1d radieals not pree. by Ba or Ag.

1. $-\mathrm{NO}_{3} \neq \mathrm{Add}$ equal volume cone. $\mathrm{H}_{2} \mathrm{SO}_{4}$, mix well, cool; on this stratify $\mathrm{FeSO}_{4}$. Brown ring. If test is positive, either $-\mathrm{NO}_{3}$ or $\mathrm{NO}_{3}$ may be presont.

2. $\mathrm{NO}_{2} \neq$ Effervesces with acids. $\neq$ Acetic acid and $\mathrm{FeSO}_{4}$ produces brown color. F AcId, KI and starch paste: blue.

3. $-\mathrm{ClO}_{3}$ small particles of dry substance (or of residue left by evaporation) gives sharp explosion with conc. $\mathrm{H}_{2} \mathrm{SO}_{4}$.

4. $-\mathrm{C}_{2} \mathrm{H}_{3} \mathrm{O}_{2}$. Wamed with $\mathrm{H}_{2} \mathrm{SO}_{4}$, and alcohol gives fruity odor of ethyl acetate. $\neq$ IF NEUTRAL, solution gives browish red color with $\mathrm{FeCl}_{3}$, prec. on bolling.

5. $-\mathrm{nnO}_{4}$. Characteristic purple color destroyed by $\mathrm{H}_{3} \mathrm{SO}_{4}$ and a sulphite.

6. $\mathrm{BO}_{\mathrm{g}}$ (Not prec. by $\mathrm{Ba}$ in very dilute solutions). see I $\mathrm{D} 4$.

7. $\mathrm{H}_{2} \mathrm{O}_{2}$. HCl and few drops $\mathrm{K}_{2} \mathrm{CR}_{2} \mathrm{O}_{7}$ gives blue color.

Absence of acid radical indicates that substance belng analyzed is an olement, oxide ór hydroxide.

The nature of the subdivisions and the reasons why such subdivisions have been made are as follows.

In Group I of those substances which from unacidified solutions form 
a precipitate on the addition of Batum chloride.

Group I, DIVision A. Substances which decompose on the addition of hydrochloric acid

ilvision B. Substaneos which form a precipitato with barium chloride in the presence of hydrochlortc acid.

Division C. Substances which form barium or calcium salts insoluble in acetic acid.

Division'D. Substances which form barium or calcium salts, soluble in acetic acid, insoluble in alkaline medium.

Group II, substances which form a precipitate with silver nitrate in the presence of nitric acid.

Division E. Substances forming silver precipitates which are dark, or darken on heating.

Division F. Substanees which, insolutions made acid with hydrochloric acid, EIve marked color with ferric chloride.

Division $G$. Place in this group due to an error.

Division H. Substances which with sodium hydroxide, ferrous sulphate, forric chloride, and hydrochloric acid (to acidity) give a blue color.

Division I. Substances which, with acids and heat liberate chlorine.

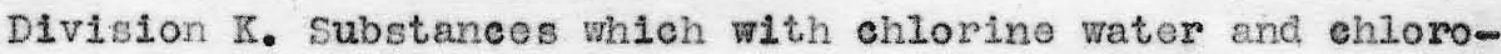
form, added to the acidifled solution, Eive marked color in the chloroform. Division L. Substaces which give a precipitate with silver nitrate in the presance of nitric acid but do not fall into any of the eroups mentioned above.

Group III. Substances which form no precipitates with barium chloride, nor with silver nitrate in the presence of nicrie acid, or form such preoipltates only in solutions of a coneontration unusual in qualitative 
The above table, which was compliled by Dr. Robinson, and used by him in his classes, though it worked well in the main still in many partieulars proved unsatisfactory. It lacked experimental foundation, and it was not known what concentrations of soro acld zadicals were requirel for the fulfillment of the tests indicated. So, in order to supply this foundation, to give accurate knowledge of what strength solutions are required, to ascertain whether or no the individual tests as given wore distinct and defintte enough for the identification of the separate radicals, to oliminate what errors might be present and to give such tests or the diseussion of given tests as would make the schene nore accurate, elearer and easily followed by the student: With the thought in mind that it must be an abbreviated seheme, only is long as needed for cleamess, and for accuracy of test, the experimental work deseribed in this paper was undertaken.

In testing solutions of the individual substances, special note has been made of percentage and of any unusual eircumstance arising. A discussion of mixtures, with in some instances a fuller diseussion of the Individual radical, is given later. The substanees are considered in the order given in the tablo above. Amonium, sodium or potassium salts were used in every case and percentages are stated in terms of these salts, generally the sodium salt. Colors are identified and named according to the Bradley o olor standard(Nulliken's "Identification of Pure organic compounds" pp 232)

I A $1=\mathrm{CO}_{3} 1 / 2 \%$ salt solution of carbonate gives a heavy gelatinous precipitate with barium chloride. Some effervesceneo on the addition of hydrochloric acid, with the slight effect on lime water. The $5 \%$ solution worked splendidiy.

I A 2, 3, 4 will be treated in II $\mathrm{E}$ where they more properily be- 
1ong.

I $B=\mathrm{SO}_{4}$ In $1 / 2 \%$ salt solution of sulphate, the formation of barium sulphate as a white precipitate was decided and immediate.

I C $1=\mathrm{C}_{2} \mathrm{O}_{4} \quad 1 / 2 \%$ salt solution givos no immediato precipitato under the conditions of the table. The $1 \%$ and $5 \%$ solutions work satisfactorily - A fuller discussion of oxalates is given later.

I C 2. $=\mathrm{Cr}_{2}$ of or $\mathrm{Cr}_{2} \mathrm{O}_{4} \quad 1 / 2 \%$ salt solution worked very well.

I C $3 .=510_{3} .5 \mathrm{co}$. of $1 \%$ salt solution eveporated to small volume $\mathrm{g}$ gives skeleton in microcosmic salt.

I B 1. $\equiv \mathrm{PO}_{4} 1 / 2 \%$ salt solution is apt to form a preeipitate in $\mathrm{C}$, but if precipitate comes in $\mathrm{C}$, it is dissolved by the addition of acetic acid. The nolybdate test gives a hedvy namal yellow precipitate, immediately with heat.

I D a. $\equiv A \mathrm{sO}_{\text {4 }} 1 / 2 \%$ salt solution with nitric acid and amonium molybdate gives a yellov coloration, a slight preeipitate form on standing some hours. Concentrated hydrochloric acid and hydrogen sulphide give a canary yellow precipitate $A s_{g} S_{5}$. This precipitate forms quickly on heating but takes sixty minutes if cold.

I D 3. $=\mathrm{SO}_{3}$ From freshly prepared solution $(1 / 2 \quad \%)$ slight effervesceno. Concentrated sulphuric acid and heat give $\mathrm{SO}_{2}$. Sulphite changes on stending to sulphate.

I. D $4 . \mathrm{BBO}_{3}$ or $=\mathrm{B}_{4} \mathrm{O}_{\mathrm{q}}$ 5ce. $1 \%$ salt solution foms a preeipitate with barium chloride. 5 c. $1 \%$ solution evaporated, on ignition gives with concentrated sulphuric acid and alcohol a nomal green flame.

I D $5 . \mathrm{C}_{4} \mathrm{H}_{4} \mathrm{O}_{6} \cdot 5 \mathrm{cc}$. of $1 \%$ solution evaporated to dryness gives heavy charring. A burnt sugar odor and syrupy Iiquid are present just befor charring. 
The-silver mirror test as given in the table, as well as a number of other tests were,tried with varying degrees of success. The row sorein test is tive most satisfactory. Add three or four drops of two per cent resorcin to tartrate solution, stratify on concentrated sulphuris acid and heat on hot water bath. A violet red ring forms at the intiersection of the two liquids, within from three to eight minutes.

II $E$ I. $=S$ One half percent salt solution gives with silver nitrate and nitric acid a heavy, immediate and dark precipitate. sulphides with sulphuric acid and heat give off hydrogen sulphide which can be detected by lts odor, and by the blackening of lead acetate paper.

II $\mathrm{E}$ 2. $=\mathrm{S}_{2} \mathrm{O}_{3}$. One-half percent salt solution works satifactorily under the conditions in the table. Theprecipitate does not turn dark as quiekly as the sulphides. Thiosulphates with sulphuric acid and heat give off sulphur dioxide which ean be detected by the; odor.

II F 1. -SCN. One-half percent salt solution gives with silver nitrate a heavy precipitate. With hydrochloric acid and ferrie chlor1de. the blood red color is instantaneous.

II $\mathrm{F}$ 2. $\mathrm{EFe}(\mathrm{CN})_{8}$. One-half salt solttion gives with nitrie acid and silver nitrate a heavy precipitate which turns blue on heating. The dark blue precipitate with ferrie chloride and hydrochlorie acid is satisfactory.

II F 3. $\equiv \mathrm{Fe}(\mathrm{CN})_{6}$. One-half\%salt solution gives with nitrie acid and silver nitrate a normal yellow orange precipitate. With hydrochloric acid and ferric chlorido a green yellow shade 2 coloration was given. With hydrochloric acid and ferrous sulphate a heavy inky blue precipitate forms. The one percent solution works the same excepting that with hydrochloric acid and ferric chloride a yllow orange shade 2 was given. The five percent solution gives with hydrochloric acid and rerric chlorido a red brown coloration. 
II F 4. -I. one-half percent salt solution gives a yellow precipitate with nitric acid and silver nitrate, with chlorine water and chloroform, a violet coloration appears in the chloroforn.

II $\mathrm{C}-\mathrm{CH}_{3} \mathrm{COQ}$

$-\mathrm{NO}_{2}$ do not belong in Group II.

II I 1. -CN. One-half percent salt solution gives a heavy white precipitate with nitric acid and silver nitrate. With sodiun hydroxide ferrous sulphate, ferric chloride, and hydrochloric acld to acidity gives a blue precipitate.

II I 1. - C10. One-half percent salt solution gives the test of this table in a decided and immediate manner.

II 1. -Br. One-half percent salt solution gives test satisfactorily acording to the table.

II $\mathrm{K}$ 2. -I. See II F 4 .

II I 1. $-C 1$. One-half pereent salt solution gives a heavy white precipitate with nitrie acid and silver nitrate. Hydrogen dioxide added to the water in which the brown fumes arising fron the nixture of the chloride and coneentrated sulphuric acid and potassium dichromate are gourod, gives a transient blue color. The test wdrks beautiful1y.

III 1. $-\mathrm{NO}_{3}$. One percent salt solution mixed with concentrated sulphuric acid stratified with ferrous sulphate heated slightly gives on standing a brom ring.

- III 2. $-\mathrm{NO}_{2}$. One-half percent salt solutioneffervesces with acids. Then nixed with concentrated sulphuric acid and ferrous sulphate stratifief thereon, a brown ring is given. A brown color forns on the addtion of acetic acid and ferrous sulphate to the nitrite solution. The salt solution when acidified turns iodice starch paper blue.

III $3-\mathrm{ClO}_{3}$. Five $\mathrm{Co}$ of one percent solution evaporated to dry- 
ness gives if concentrated sulphuric acid is dropped upon it disagreoable brom funes. of chlorine dioxide, and chlorine fumes. If the temperature Is above $60_{0}^{\circ}$, a sharp explosion occurs.

III 4 $-\mathrm{CH}_{3} \mathrm{COO}$. The Perric chloride test for reasons given later is onltted. $10 \mathrm{ce}$. of one-half percent or five ce. of one percent salt solution evaporated to dryness gives with a mixture of 3 ce of etricl alcohol and 3 ce. of concentrated sulphuric acid fruity odor of ethyl acetate; if an excess of acid; acetic acid ofor is given. 5 ce. of one per cent salt solution gives a slight charring.

III 5. $-\mathrm{MnO}_{4}$. One-half per cent solution works satisfactorily.

III 6. $=\mathrm{BO}_{3}$. Not precipitated by barium chloride in dilute solutions. See I B 4 .

III \%. $\mathrm{H}_{2} \mathrm{O}_{3}$. One-halr per cont solution gives with hydrochloric acid and potassium dichromate a transient blue color.

From the foregolng data, and other considerations, various changes in the analytieal table were seen to be necessary, and the following revised table embodies these corrections.

Analytical rables. Tests for Acid Radicals.

If the original solution contain metals other than the alkalies, add to about $50 \mathrm{ce}$. of it enough sodiun carbonate to make strongly alkaline, boil ten to fifteen minutes, renewing water lost by evaporation, and filter. Use this prepared solution for the acid analysis, except for the carbonate test, and when specially direeted to use the orig'inal solution.

Perform the tests in the order indicated.

fmeans take fresh portion of prepared solution.

I. If the original solution contains acid, work through $B, C, D$. If unacidified, ade to a portion of it barium chloride and heat. If no precipitate form proceed at once to II. If precipitate occurs, work 
through $A, B, C$, and $D$.

A. F To a portion of the prepared solution add hydrochloric acid (one to ten drops) -to slight acldity. Effervescence indicates (unless sodium carbonate was added aboved

1. $=\mathrm{CO}_{3}$. Passing gas into lime water gives preeipitate. Gas has no erfect on $\mathrm{KannO}_{\mathrm{a}}$.

Precipitate of Sulphur indicates

2. $\mathrm{S}_{\mathrm{Z}} \mathrm{O}_{3}$. Heated gives $6 \mathrm{Pe} \mathrm{SO}_{\mathrm{B}}$. Recognizable by odor, $\mathrm{KunO}_{4}$ when added decolorized.

3. $=\mathrm{S}_{\mathrm{x}}$

4. $=S+$ oxidizing agent. See II, $\mathbb{E}, 1$.

Gelatinots precipitate indicates

5. $=\mathrm{SiO}_{\mathrm{s}}$. See C 3 .

B. Filter clear add $\mathrm{BaCl}_{3}$, white precipitate.

1. $=\mathrm{SO}_{4}$.

C. Filtor clear, boil to remove $\mathrm{CO}_{3}$, add $\mathrm{CaCl}_{2}$ ( a few crystals) and one to two grans sodium acetate. Boll, teaction must renain acid, procipitate (insoluble in acotie acid) indicates:

1. $=\mathrm{C}_{2} \mathrm{O}_{4}$. Filter, wash, treat gree. With dilute $\mathrm{H}_{2} \mathrm{SO}_{4}$, - warm and add $\mathrm{minO}_{4}$, decolorized.

2. $=\mathrm{Cr}_{8} \mathrm{O}_{\mathrm{q}} \cdot-\mathrm{CrO}_{4}$. If yellow. Filter, wash, dissol ve in HCl, add $\mathrm{H}_{2} \mathrm{O}_{2}$, a transient bluo color.

3. $=\$ \mathrm{SO}_{\mathrm{g}}$. Ivaporate $5 \mathrm{ce}$. of acidified aolution ot dryness . Residue mtaphosphate bead (microcosmic salt) gives a siceletón.

D. Filter clear, make alkarine with $\mathrm{Ba}(\mathrm{OH})_{2}$ (use 1itmus, if neeessary evaporate to original concentration) Precipitate indicates:

1. $\mathrm{PO}_{4} \neq$ acidify with nitric acid, add ammoniun molyb- 
date, on heating (not above $60^{\circ}$ ) heavy nomal yellow prec.

2. $\mathrm{AsO}_{4}$. $\neq \mathrm{Add}$ cone. $\mathrm{HCl}, \mathrm{H}_{2} \mathrm{~S}$ and heat. A canary yellow pree. f Molybdate test, on heating and standing some hours.

3. $=\mathrm{SO}_{3}$. $\neq \mathrm{H}_{2} \mathrm{SO}_{4}$ and heat givos $\mathrm{SO}_{3}$. $\mathrm{KunO}_{4}$ decahorized.

4. $\equiv \mathrm{BO}_{3}$, or $=\mathrm{B}_{6} \mathrm{O}_{\mathrm{r}} \cdot$. Solid material or material evaporated to vory small volume gives with cone. $\mathrm{I}_{\mathrm{a}} \mathrm{SO}_{4}$ and alcohol a greer flame when ignited.

5. $\mathrm{C}_{4} \mathrm{H}_{4} \mathrm{O}_{6}$. $\#$ Evaporate 5 ce. of solution to dryness and heat the rosidue, heavy charring, burnt sugar odor, syrupy

liquid just before charring. $\neq$ To $3 \mathrm{cc}$, add from two to four drops $2 \%$ resore in solution stratify on cone. $\mathrm{H}_{2} \mathrm{SO}_{4}$. Alviolet red ring forns in from three to elght ninutes if heated on the water bath.

II. F Acidify with $\mathrm{INO}_{3}$ and add $\mathrm{AgNO}_{3}$. If no proe. forms, prooeed at oneet III. If pree., work through I to I.

E. Silver pree. dark, or darkens when heated.

1. $=\mathrm{S}$. Silver prec. darkents innediately. $\neq \mathrm{H}_{8} \mathrm{SO}_{4}$ and heat give $\mathrm{H}_{2} \mathrm{~S}$ detected by odor, and by lead acetate paper being blackened in vapors.

2. $=\mathrm{S}_{3} \mathrm{O}_{3} \cdot \neq \mathrm{H}_{2} \mathrm{SO}_{4}$ and heat give prec. of $\mathrm{S}$ and $\mathrm{SO}_{2}$. detected by odor and decolorization of $\mathrm{Kann}_{4}$.

F. $\neq$ Gives marked color with HCI and $\mathrm{FeCl}_{3}$.

1. -SCN blood red solution with HCI and $\mathrm{FeCl}_{3}$.

2: Fe(at) $_{3}$ Daris blge pree. With Hel and $\mathrm{FeCl}_{3}$. Silver

- pree blue on heating.

3. $\equiv \mathrm{Fe}(\mathrm{CN})_{6}$ Dirty brom. $\neq \mathrm{HCI}$ and $\mathrm{FeSO}_{4}$ deep blue pree. silver prec, orange.

4. -I brown with HCI and $\mathrm{FeCI}_{3}$. Chloroform added and shaken assumes violet color. $\neq$ silver prec. yellow.

G. $\neq \mathrm{NaOH}, \mathrm{FeSO}_{4}, \mathrm{FeCl}_{3}$, and $\mathrm{HCl}$ to acidity, blue prec. indieates 
3. -in (not applicable in $\mathrm{FL}$ and $\mathrm{F}_{3}$.)

H. $\neq$ gives $\mathrm{Cl}$ with acids and heat (starch-iodide paper in vapor turns blue)

1. -C10 $\neq$ acidified bleaches indigo solution.

I. $\neq$ Chlorine water and chloroform added to slightly acidified solution. Color in latter indieates,

1. -Br gives chlorofor brown color.

2. - I gives chloroform violet color. Carefully add excess of chlorine water until violet disappears ( $\mathrm{ICl}_{\mathrm{s}}$ ). If brown remains, both $\mathrm{Br}$ and I are present.,

I. If all previous tests in section II are negative, the silter precipltate must be $\mathrm{AgCl}$, indicating $-\mathrm{Cl}$. Precipitate readily soluble in $\mathrm{NH}_{4} \mathrm{OH}$. If other acid radicals of this section are present, mix portion of dry substance or residue left by evaporation of solution with powereod $\mathrm{K}_{2} \mathrm{Cr}_{2} \mathrm{O}_{7}$ in dry test tube, add $5 \mathrm{cc} . \mathrm{H}_{2} \mathrm{SO}_{4}$ and warm. Pass bromine fumes into water mixed with $\mathrm{H}_{2} \mathrm{O}_{2}$. Transient blue color indicates C1. (Dangerous if chlorates are present, apply test III, 3 , to deted chlorates). III. Acid radicals not precipitated by $\mathrm{Ba}$ or Ag.

1. $-\mathrm{NO}_{3} \neq$ add equal volume cone. $\mathrm{H}_{2} \mathrm{SO}_{4}$, mix well, cool, on this stratify with pipette $\mathrm{FeSO}_{4}$. Brown ring. If test is positive, either $-\mathrm{NO}_{3}$ or $-\mathrm{NO}_{\mathbf{3}}$ may be present.

$-\mathrm{NO}_{2} \neq$ acid $+\mathrm{KI}$ starch paste, blue. If both $-\mathrm{NO}_{3}$ and $\mathrm{NO}_{2}$ axe present add acetic acid and urea erystals. Boil till a few dreps give no color with $\mathrm{FeSO}_{4}$, showing that $\mathrm{NO}_{2}$ is no longer present. Cool, apply ring test.

2. $-\mathrm{ClO}_{3}$ Dropping cone. $\mathrm{H}_{2} \mathrm{SO}_{4}$ on particles of dry substance (or residue left by evaporation) liberates disagreeable brown fumes $\mathrm{ClO}_{3}$, also C1. Sharp explosion may occur.

4. $-\mathrm{C}_{3} \mathrm{H}_{3} \mathrm{O}_{3}$. Evaporate 5 to $10 \mathrm{cc}$. to suall volume in evaporating dish. Add $3 \mathrm{ce}$. ethyl alcohol and $3 \mathrm{cc}$. conc. $\mathrm{H}_{2} \mathrm{SO}_{4}($ well mixed so that 
odor of alcohol in annihilated), heat, fruity odor, ethyl acetate. If excoss of sulphuric acid, acetic acid odor.

5. $-\mathrm{inO}_{3}$. Characteristic purple color destroyed by $\mathrm{H}_{2} \mathrm{SO}_{4}$ and a sulphite. Add a sulphite crystal, for the solution changes rapidly to sulphate.

6. $\equiv \mathrm{BO}_{3}$. ( Not precipitated by barium salt in very dilute solutions) See 1 D 4.

7. $=\mathrm{C}_{4} \mathrm{H}_{4} \mathrm{O}_{6}$. (Way not be precipitated by Bacl. See $I$ D 5.)

8. $\mathrm{H}_{3} \mathrm{O}_{2}$. HCland a few drops of $\mathrm{K}_{2} \mathrm{Cr}_{2} \mathrm{O}_{7}$ gives a blue color. Absence of acid radieal indicates that the substance being analyzed is an element, oxide, or hydroxide.

I have substituted the charring and resorein tests for tartrates in the place of the silver mirror test, for the latter does not work satisfactorily. Some authorities Give only the charring test for the detection of tartrates. But as other organic acids also char, it is wise to have the resorcin test for confirmation. The resorein test gives with tabtrates the normal violet rod coloration -with lactic acid, one percent salt solution gives a normal gray yellow, with five porcent gives yellow shade one with citric acid one percent solution gives no coloration and five percent gives orange gellow shade two.

As some substances do not precipitate readily with bariun chloride, but do so more readily when hot than cold, the word heat" was inserted in the directions for group one. Then in directions for precipitating division $C$ group one the words"insoluble in acetic acid" because the phosphates are nearly always precipitated in division $C$, their precipitates thus forned are dissolved upon the addition of acetic acid. In the test for acetates the words," if neutral solution gives brownish red color 
with ferric chloride, precipitate on boiling " were onited. Because ferric chloride alone gives a nomal orange red coloration, due to the hydrolysis of ferric chloride and the formation of the precipitate ferric hydroxide, this, however, on boiling changes to normal yellow orange. The solution of ferric chloride and an acetate is normal red which on boiling yields a red orange shade one precipitate. While the two precipitates differ several shades in color, still the two solutions differing by only one shade (rod for acetate solution and orange red for the ferric chloride solution) and the fact that both on boiling yield precipitates, are apt to mislead the student.

As sulphites in solution are changed so rapidly to sulphates, I have found in testing permanganates,. III 5, it is most satisfactory to add sulphite crystal than a solution.

Division G group II was onjied. Because group two was to consist of substances which gave a precipitate with silvor nitrate in the presence of nitric acid. If Fifty percent acetate solution with pure silver nitrate crystals formed a precipitate, which was partially dissolved upon the addption of dilute nitric acid to the test tube containing it. $A$ twenty-five porcont acetate solution to which wes added pure silver nitrate crystals ylelded a precipitate whic dissolved in dilute nitric acid. A flfty perpent acetate solution with dilute nitric acid and silver nitrate ( onehalf percent, the same as use throughout the experiments) yielded a faint loudiness but no precipitate. A fifty percent ritrite solution yielded rith nitric acid and silver nitrate brom fumes and a precipitate, as did the twenty-five pereent and twelve and one half percont, in each case he precipitate was decreasing in amount. Below twelve and one half percent olutions, there was à very faint precipitate due in all prowability to chloride, as no chloride-free nitrite was obtainable. In general, the olutions used for qualitative analysis are not more than five percent, if 
hat strong; and as nelther acetatespor nitrites of that percentage yield precipitate with nitric acid and silver nitrate, it is advisable to mit division G group it of the original table.

In the table as revised all the individual tests have been provon. 6 that the scheme will afford no trouble whatever in the detection of the acid radical of a single salt. How we will give the results obtained Ith this table in using a mixturo of two salts and in some ingtances pre detailed information concoming the individual acid radicals.

In all the following tests one percent salt solutions were used. Carbonates may be successfully detected when mixed with sulphided, hiosulphates, sulphocyanides, ferrocyanides, ferricyanides, Iodides, yanides, hypochlorites, bromides, chlorides, nitrates, nitrites, chlorates, cetates, permanganates, and hydrogen poroxide.

Oxalates may be dotected with sulphides, thiosulphates, sulphopahides, ferrocyanides, Eerricyanides, lodides, cyanides, hypochlorites, pomides, chlorides, nitrates, nitrites, chlorates, acetatos, and hydrogen proxides but not very successfully with permanganates.

Phosphates may be detected with sulphides, thiosulphates, sulphoanides, ferrocyanides, ferricyanides, lodidos, bromides, cyanides, hypolorites, bromides, chlorides, nibrates, nitrites, chlorates, acetates, manganates, borates, and hydrogen peroxide.

In all the above cases phosphate precipltate was forned in division proup I, this procipitate dissolved upon the adddtion of acetic acid, forwise the tests were satisfactory. With ferrocyanide a red brown ofiplate formed in trying the molybdate tost, on heating, however, the color disappeared leaving the characteristic yollow. With sulphides and iosulphates a green color is obtalned with molybdate test, these too dispear on heating leaving the canary yellow precipitate due to the presence phosphatos. With lodidos and molybdate test a daris greon coloration is 
lormed, which with heating gave of purple fumes (lodine) on boiling hard for five minutes an orange solution and yellow precipitate appear, on bollIn several more minutes we obtain the desired canary yellow precipitate. If color other than phosphate yellow is present, the addition of nitric acid helph to drite it off more quickly.

Arsenates may be successifully tested for when mixed with sulphides, thiosulphatos, sulphocyanates, ferrocyanides, ferricyanides, iodides, Cyanides, hypochlorites, bromides, chlorides, nitrates, nitrites, chlorates, acotates, permanganates, borates, and hydrogen peroxide.

A number of tests often used for tartrates were tried out, with the pllowing results. 1. Add ferrous sulphate or chlorlde, a litice sodium peroxide, and excess of sodium or potassium hydroxide, a purple color is. given. This color is given only when saturated or vory concentrated solutions of taptrates are used. 2. The silver mirror test with nitric acid, HIver nitrate, and ammonium hydroxide is not dependabze. 3. A tartrate solution plus dilute sulphuric acid one cr two drops of potassim chromate, leated some tine gives a yellow color which changes to blue violet. The flve percent solution gave a good green vielet coloration, the one percent a groenish. This peaction is given by other organic acid s. 4. Add reakly acid amnonium molybdate to tartaric acid, orie or two drops of hydrogen peroxide or a trace of sodium perexide ( not more), heat gentiy blor changes from wine to green then to blue. This test did not work satisfactoríy. 5. A fow drops of resorcin in concentrated sulphuric acid ramed until the sulphuric acld vapors just begin to escape, the 11quid assumes a wine color. This last test with five pereent tartrate solution gave a bead of nomal red which charrod on standing, the one percent solution gave a boad of violet red tint one which changes to red tint one. Hodifying the above mothod of the pesorcin tost, in that a two porcent 
resorcin solution, was used, mixed. with the tartrate solution, and the mixture btratified upon concentrated sulphuric acid and heated gently. One drop of two percent resorein to one percent tartrate solution was sufficient to give a slight violet rod ring, on being heated to a slight boil, wwo drops of the resorcin solution gave a more decided test on being hoated, The ring increasing on standing. While fthroe or four drops of resorcin solution are added there would be no doubt as to the identification of the tartrate, All of the above char on standing. In a hot water bath the violet red ring was formed with the one, two, three, or four drops of resorcin in from three to eight minutes.

Tartrates may be tested for, according to the above scheme with no ajterations in the ease of the mixture of tartrates with, sulphocyanates, thiesulphates, chlorides, acetates, borates, and cyanides. In the case of the cyanides the concentrated sulphuric acid has to be added carefully as the formation of hydrocyanic acid and tits evolution as a gas spolls the test. Tartrates with ferrocyanides, ferricwankdes, and lodides, forn littlo or no precipitate with barium chloride. With sulphidles, ferrocyanidos, ferricyanides, lodides, and bromides the tartrate is precipitated In division C. With ferrieyanide the perception of the violet rod ring of the resorein test is marred by the presence of a heavy dark procipitate. With a mixture of tartrates and iodides there lis this difficulty, for while the tartrates give the violet red color, with resorcin and concentrated sulphuric so do lodides. If only the two are present, the precipitate in division D group one would show the presenco of tartrateis and preelpitation in group two the prosence of an iodide. But there may bo other radicals of division D prosent so we have to resort to the charring test for tartrates. $2 \mathrm{cc}$ of one percent tartrate solution in a crucible cover gives an extremely heavy char. So much so that this test is often given as the only test for 
the detection of tartrates in mixtures. Acetates give a slight char, oxalates a very slight one if any. W1th bromides and the resorcin test, the ring instead of being violet rod is blue, (though in one instance the ring is violet red) due to bromine interferrence. If an excess of bromide be added the violet red ring changes to blue, this was shown by other experiments to be due to the liberation of bromine. In mixtures of tartrates and hypochlorites the hypochlorites act on the resorein Giving an evanoscebt purple color. If a mixture of one peroent hypochlorite and one porcent tartrate is used the resorcin test is still good. But is the mixture contains twico as mach hypechlorite as tartrate a brom ring is formed. The resorcin test is of no aval. with nitwates, nitrites, chlorates, permanganates, and hydrogen peroxide. Sulphites may be detected in the presence of carbonates, oxalates, phospiates, arsenates, tartrates, bromides lodides, and nitrates. Thiosulphates may be detected in the presenco of oxalates, phosphates, arsenates, tartrates, bromides, lodldes, and nitrates. Sulphocyanides may be detected in the presence of carbonates, oxalates, phosphates, arsenates, tartratws, and borates.

Ferrocyanides may be detected in the presence of earbonates, oxalates, phosphates, arserates, tartrates, and borates.

Ferricyanides may bo decected In the presence of carbonates, oxalates, phosphatos, tartrates, borates, and arsenates.

Iodides mag be detocted in the presence of carbonates, oxalates, phosphates, arsenates, tartrates, borpates, and nitrates by the chloroform, chlorine water test: But if the lodides be mixed with elther a sulphide or a thiesulphate the chloroform, chlorine water test 1s no good. If you heat a mixture of sulphides and lodides with concenb trated nitric acid to destroy the sulphte, purplo lodine vapors will be given off before all the sulphide is destroyed. If to a mixture of 
an lodide and thiosuiphate you add coneentrated nitric acld and chloroform the lodine eoloration is given.

Cyantdes may be dotected. In the presence of carbonates, oxalates, phosphates, arsenates, and tartrates.

Hypochlorites may be detected in the presence of carbonates, oxalates, phosphates, arsenates, and tartrates.

Bromides may be detected in the presence of carbonates, oxalates, phosphates, arsenates, tartrates, and nitrates, If the bromide is mixod with a sulphice or a thiosulphate the chlorine water test w111 not work until the sulphido or thiosulphate has been destreyed this may $b$ o done with concentrated nitric acid.

Chlorides may be dotected in the presence of carbonates, oxalates, phosphates, assenates, and tartrates.

Nitretes may we detected in the presence of carbonates, oxalates, phosphates, arsenates, tartrates, bromides, and iodides. Nitrates whon mixed with sulphides and thiosulphates are changed to nitrites.

Mibritos may be deteoted in the presenee of carbonates, oxalates, phosphatos, arsonatos, and tartrates.

Chlorates may bo dotected in the presence of earbonates, oxalates, phosphates, arsenates, and tartrates.

Acetates may be detected in th presence of carbonates, oxalates, phosphates, arsenetes, and tartrates.

Pemanganates may be detected in $t$ o presence of carbonates, oxalates, arsenates, and tartrates. If the permanganate is mixod with a phosphate, the pemanganate will not be decolorized by a sulphite, but will be by a sulphide.

Borates may be deteotod in the presence of phosphatos, arsenates, tartrates, sulphocyanides, ferrocyanides, ferrioyanides and Lodides. Hydrogen peroxide may be detected in the presence of oxalates, 
phosphates, arsenates, tartrates, and freshly prepared solutions of carbonates. If the mixture of hydrogen poroxide and carbonates is allowed to stard for a day of se, the hydrogen peroxide test will not be given.

In working the foregoing experiments reagents of tho following strengths were used, unless otherwise spocifled. Sodium hydroxide, amonium hydroxide, ammonium chloride, sulphuric acid, hydrochleric aci d, and nitric acid were threo-nomal. Ammonium carbonate and acetio acid twice-nomal. Sodium carbonate was a normal solution, Barlum chloride, Perric chlorice, potessium dichromate, and lead acetate were halfnormal. Potassium ferrocyanide wes fourth-nomal and the sliver nitrate was one-half of one peroent. 